\title{
O PROGRAMA IDIOMAS SEM FRONTEIRAS COMO POLÍTICA PÚBLICA EDUCACIONAL
}

\author{
EL PROGRAMA “IDIOMAS SEM FRONTEIRAS” COMO POLÍTICA PÚBLICA \\ EDUCACIONAL
}

\author{
THE "LANGUAGES WITHOUT BORDERS” PROGRAM AS AN EDUCATIONAL \\ PUBLIC POLICY
}

\author{
Eduardo José PACHECO ${ }^{1}$ \\ Luciana Beatriz de Oliveira Bar de CARVALHO ${ }^{2}$
}

RESUMO: O desenvolvimento do programa Ciência sem Fronteiras, que permitiu a universitários brasileiros estudarem temporariamente no exterior, teve alguns entraves. Um deles foi a falta de proficiência em idiomas estrangeiros entre os candidatos. Como solução para supri-la, foi criado o programa Idiomas sem Fronteiras (IsF). Este estudo objetivou construir uma compreensão teórico-conceitual do IsF como política pública. Trata-se de pesquisa qualitativa bibliográfico-documental cujas fontes foram documentos relativos ao IsF, informações de bases de dados do governo e outras. O referencial teórico-conceitual incluiu Secchi (2015), Rodrigues (2015), Goodin, Rein e Moran (2006), Majone (1989) e outros. Os resultados situam o IsF como política pública (como solução de problema público) cuja criação se desdobrou em um ciclo (elaboração, implementação, avaliação e conclusão). Como tal, o IsF passou por reformulação para ser continuado. A continuidade é seu ponto crítico em razão dos investimentos necessários em qualidade da educação básica, desenvolvimento das ciências e tecnologia.

PALAVRAS-CHAVE: Proficiência em idiomas. Idiomas sem fronteiras. Política pública.

RESUMEN: El desarrollo del programa "Ciência sem Fronteiras", que permitió a los estudiantes universitarios brasileños estudiar temporalmente en el extranjero, tuvo algunos obstáculos como la falta de competencia de los candidatos en hablar idiomas extranjeros. Como solución, se creó el programa "Idiomas sem Fronteiras" (IsF). Este estudio buscó construir una comprensión teórica-conceptual del IsF como política pública. Es una investigación bibliográfica-documental cualitativa basada en documentos del IsF, informaciones gubernamentales y otras. Sus referencias conceptuales fueron Secchi (2015), Rodrigues (2015), Goodin, Rein y Moran (2006), Majone (1989) y otros. Los resultados muestran el IsF como política pública (solución a un problema público) cuya creación se desarrolló en un ciclo (de elaboración, implementación, evaluación y conclusión). El IsF continua activo después de reformulaciones; pero su continuación aun es crítica porque

${ }^{1}$ Instituto Federal Goiano (IF Goiano), Rio Verde - GO - Brasil. Pedagogo. Mestre em Educação (UNIUBE). ORCID: https://orcid.org/0000-0001-9804-0702. E-mail: eduardo.jpacheco@hotmail.com

${ }^{2}$ Universidade de Uberaba (UNIUBE), Uberaba - MG - Brasil. Professora do Programa de Pós-graduação em Educação. Doutorado em Educação (UNICAMP). ORCID: https://orcid.org/0000-0002-2005-6277. E-mail: lucianabeatrizcarvalho@yahoo.com.br

RPGE- Revista on line de Política e Gestão Educacional, Araraquara, v. 25, n. 1, p. 103-122, jan./abr. $2021 . \quad$ e-ISSN:1519-9029 DOI: https://doi.org/10.22633/rpge.v25i1.13650 
depende de inversiones en la calidad de la educación básica, en el desarrollo de la ciencia y en la tecnología.

PALABRAS CLAVE: Competencia en idiomas. Idiomas sem fronteiras. Política pública.

ABSTRACT: The development of the Science Without Borders program, which allowed Brazilian university students to study abroad for a period of time, had some obstacles. One of them was the lack of proficiency in foreign languages among candidates. As a solution to correct it, the program Languages Without Borders (IsF, Portuguese initials) was created. This study aimed to build a theoretical and conceptual understanding of IsF as a public policy. This is a qualitative bibliographic-documentary research, whose sources were documents related to the IsF, information from government databases and others. The theoretical-conceptual framework included Secchi (2015), Rodrigues (2015), Goodin, Rein and Moran (2006), Majone (1989) and others. The results place Is $F$ as a public policy (as a solution to a public problem) whose creation unfolded in a cycle (planning, implementation, evaluation and conclusion). As such, IsF underwent reformulation to be continued. Continuity is its critical point due to the necessary investments in quality of basic education, development of science and technology.

KEYWORDS: Language proficiency. Languages without borders. Public policy.

\section{Introdução}

Em 24 de abril de 2007, dois decretos federais (n. 6.094 e 6.096) instituíram o Programa de Apoio a Planos de Reestruturação e Expansão das Universidades Federais (REUNI) e o plano de metas-compromisso Todos pela Educação. Tais iniciativas foram o início da concretização de uma agenda de políticas público-educacionais cujos desdobramentos incluíram, por exemplo, a criação do programa Ciência sem Fronteiras. Por meio deste, universitários matriculados em Instituições de Ensino Superior públicas tiveram a oportunidade de estudar no exterior por determinado período de tempo. Uma das condições para aproveitar essa possibilidade era ter domínio da língua oficial do país escolhido como destino. A fim de dar suporte aos estudantes quanto a desenvolver competências linguísticas em idiomas estrangeiros, foi criado o Idiomas sem Fronteiras (IsF), formalizado pela portaria 1.466, de 18 de dezembro de 2012, e cujo desenho enfocou a língua inglesa de início e outros idiomas depois.

Com efeito, tais iniciativas passaram a ser objeto de discussão, seja entre grupos de interesse, grupos políticos, mídia ou pesquisadores ${ }^{3}$. Mas o IsF ficou um tanto quanto alheio ao

${ }^{3}$ Estudos acadêmicos sobre o IsF incluem: "O Programa Idiomas sem Fronteiras analisado a partir do ciclo de políticas" (2015), artigo de Thomás Dorigon (2015); "Inglês sem Fronteiras: uma mirada ao contexto de prática pelo prisma da formação de professores" (2015), artigo da professora Simone Sarmento, ex-vice-presidente do IsF, em coautoria com William Kirsch e voltado à formação de professores; "A implementação do programa Inglês sem Fronteiras na Universidade Federal do Rio Grande do Sul" (2013), trabalho de conclusão de licenciatura de RPGE- Revista on line de Política e Gestão Educacional, Araraquara, v. 25, n. 1, p. 103-122, jan./abr. $2021 . \quad$ e-ISSN:1519-9029 DOI: https://doi.org/10.22633/rpge.v25i1.13650 
debate, assim como ao interesse dos universitários. No caso destes últimos, o "desinteresse" pela oportunidade que tal iniciativa ofertava foi patente nos chamados Núcleos de Línguas (NucLi) formados em universidades federais para suprir a demanda por aprendizagem de línguas estrangeiras associada ao IsF. Exemplo do alheamento ao IsF foi notado na Universidade Federal do Triângulo Mineiro, em Uberaba, $\mathrm{MG}^{4}$. A experiência docente no NucLi dessa instituição foi circunstância para observar a baixa procura pelos cursos de línguas. Contudo, conversas com professores de outros núcleos em eventos como o encontro nacional do IsF, em Brasília, DF, apontaram que o problema não era local.

Apesar dessa falta de projeção, sobretudo em meio ao seu público-alvo, o IsF se expandiu em curto período de tempo, a ponto de sua existência e manutenção demandarem investimentos financeiros do governo federal para suprir a necessidade criada nas universidades participantes do Programa. Mais que isso, enquanto o Ciência sem Fronteiras cessou, o IsF continua ativo; e essa condição subjaz as motivações deste estudo para especular esta questão: o que significa chamar o IsF de política pública da educação? Ou seja, o que é o IsF como política pública? O estudo aqui apresentado partiu dessa indagação com o objetivo de construir uma compreensão teórico-conceitual do IsF, do contexto de seu surgimento e de suas potencialidades como política pública.

A pesquisa subjacente a este se desdobrou segundo preceitos da pesquisa qualitativa, tendo em vista que as ações associadas com a existência e o funcionamento do IsF derivaram da tomada de decisões que não ficaram isentas de contradições. Igualmente, a compreensão almejada com a pesquisa se vinculou à vivência da prática docente nas atividades prescritas pelo Programa. Vivência essa repleta de subjetividades e vontades individuais, dentre outros atributos que permeiam a ação educacional. Nesse sentido, a abordagem qualitativa se fez pertinente porque - como diz Chizzotti (2014, p. 26) - presume a realidade objetiva como "fluente e contraditória", ou seja, como algo que não tem "padrão único"; além disso, supõe processos de pesquisa que “[...] dependem também do pesquisador — sua concepção, seus valores, seus objetivos".

Bruno Scortegagna (2013); enfim, "Inglês sem Fronteiras: contribuições para a internacionalização da educação superior brasileira" (2015), texto de apresentação de Ana Cristina da Silva Brito. Convém notar que a professora Simone Sarmento, ex-vice-presidente do IsF, coordena o grupo de pesquisa "O papel das políticas educacionais linguísticas na internacionalização das universidades: os efeitos do Idiomas sem Fronteiras”, voltado a políticas públicas, mas focalizado na internacionalização e no envio de brasileiros para o Canadá. Não por acaso, o trabalho de Scortegagna foi orientado por ela.

${ }^{4}$ Por quase dois anos, Eduardo Pacheco (coautor deste) atuou como membro do corpo docente do IsF em Uberaba, MG.

RPGE- Revista on line de Política e Gestão Educacional, Araraquara, v. 25, n. 1, p. 103-122, jan./abr. $2021 . \quad$ e-ISSN:1519-9029 
A pesquisa se desdobrou mediante procedimentos como leitura crítica de bibliografia teórico-conceitual sobre políticas públicas e levantamento de documentos relativos ao IsF (decretos, portarias, normas internas e outros que pudessem ser úteis à análise e discussão) e de informações contidas em bases de dados do governo federal (Sistema Eletrônico do Serviço de Informação ao Cidadão, Portal da Transparência e website do IsF). O produto de tal levantamento constituiu o corpus de fontes da pesquisa, ao qual se agregaram entrevista com a presidente do núcleo gestor do IsF e dados do livro Do Inglês sem Fronteiras ao Idiomas sem Fronteiras: a construção de uma política linguística para a internacionalização ${ }^{5}$, produzido por membros do núcleo e que contém elementos de uma visão coletiva interna do IsF.

A pesquisa se valeu de referencial teórico que pudesse embasar uma compreensão sólida do processo de constituição de uma política pública. Nesse sentido, a visão de Secchi (2015) foi central; mas não foi a única. Também foi considerado o que dizem Rodrigues (2015), Goodin, Rein e Moran (2006), Majone (1989) e outros sobre política pública.

O desenvolvimento do estudo considerou dois campos contextuais. Uma vertente de contextualização incidiu na compreensão do IsF como política pública, considerando seu histórico, seu desenho e tendo como marco legal temporal a portaria de 2012, que o criou. Outra vertente abrangeu a discussão sobre políticas públicas, considerando o IsF segundo seu ciclo (de etapas) como política pública, conforme (SECCHI, 2015). São apresentados conceitos de política pública, em especial de seu funcionamento, e os atores nela envolvidos (o modo como agem).

\section{O conceito de política pública}

Com efeito, as bases teóricas e metodológicas sobre as quais se funda o conceito de política pública ainda se mostram difusas e pouco claras. Não faltam definições de política pública, dentre as quais Souza (2006) reuniu algumas. Exemplos incluem a definição de Mead (1995) - que define política pública como objeto de estudo da política pertinente ao governo e suas questões de ordem públicas; a de Lynn (1980) - que vê política pública como ação governamental destinada a ter reações específicas; a de Peters (1986) — que trata de política pública como soma de atividades governamentais de influência na vida do cidadão em que as ações podem emanar diretamente do governo e serem delegadas; enfim, a definição de Dye

${ }^{5}$ O livro, Do Inglês sem Fronteiras ao Idiomas sem Fronteiras: a construção de uma política linguística para a internacionalização, foi publicado pela editora da Universidade Federal de Minas Gerais, em 2016.

RPGE- Revista on line de Política e Gestão Educacional, Araraquara, v. 25, n. 1, p. 103-122, jan./abr. $2021 . \quad$ e-ISSN:1519-9029 DOI: https://doi.org/10.22633/rpge.v25i1.13650 
(1984) — para quem política pública é aquilo que o governo opta por realizar ou não. Em que pese o tom sintético de tais definições, importa notar que estão centradas no Estado, isto é, presumem a ação do governo (seja federal, estadual ou municipal).

Autores com Secchi (2015), Goodin, Rein e Moran (2006) e Rodrigues (2015) dão ênfase à ideia de política pública como processo voltado à resolução de problemas. No dizer de Secchi (2015, p. 9), “[...] o conceito de política pública está vinculado à tentativa de enfrentamento de um problema público". Nesse caso, o problema distingue situação ideal e status quo. Cabe esclarecer que dada situação passa a ser problemática quando passa a ser vista como tal por muitas pessoas ou um ator (individual ou coletivo) que influi, por exemplo, na esfera política ou que pode providenciar ações em favor de uma solução. O problema pode até ser perene na realidade cotidiana das pessoas, ou seja, ficar sem solução por muito tempo, de tal modo que elas se acostumam a conviver com ele. Igualmente, pode surgir de repente ou aparecer de forma discreta e crescer aos poucos. Sobretudo, o problema pode ser subjetivo, pois as pessoas enxergam e entendem a realidade diversamente.

Dito isso, enquanto Secchi (2015) trata de política pública como diretriz para solucionar problema de interesse público, Goodin, Rein e Moran (2006) a veem como resposta a um problema. A seu turno, Rodrigues (2015, p. 13) entende política pública como processo em que grupos sociais marcados por "interesses, valores e objetivos divergentes" decidem, coletivamente, em nome do todo da sociedade. Nesse sentido, o destino da política pública seu alvo, seus destinatários - é conhecido como os policytakers (algo como os recebedores ou consumidores da política pública). Muitas vezes, podem ser atores passivos da política pública; mas, como diz Secchi (2015, p. 115), há condições em que os destinatários podem não só dar forma à opinião pública, mas ainda articular o interesse de grupos difusos.

Com efeito, por ser de interesse coletivo, o problema público pressupõe a associação e o envolvimento de vários agentes cujos interesses variam quanto à solução ou manutenção dele. São os atores das políticas públicas. A literatura das ciências políticas os concebe como indivíduos e grupos/organizações que desempenham papéis na arena política, em frentes diversas. Em um processo de política pública, os atores relevantes vão além do governo, pois incluem os que, direta ou indiretamente, influenciam o conteúdo e os resultados; sobretudo, os que sensibilizam a opinião pública quanto a problemas de relevância coletiva. Os atores influem na decisão do que entra ou não, por exemplo, na agenda governamental; estudam e elaboram propostas; decidem e convertem intenções em ações (SECCHI, 2015). 
Como indivíduos, os atores podem ser um político com cargo eletivo; uma personalidade midiática, ou seja, que age na opinião pública; um empresário que controla meios de comunicação; um cidadão comum com rede de contatos relevantes; enfim, pode ser um partícipe das várias etapas operacionais que marcam a implementação ou execução da política pública. Como coletivo, os atores podem ser organizações, públicas ou não; por exemplo, instituições e órgãos governamentais, partidos políticos, associações, sindicatos, empresas de personalidade jurídica pública ou privada, dentre outras passíveis de influenciar a opinião pública, representar grupos de interesses comuns e desempenhar, direta ou indiretamente, dado papel nos atos decisórios. Os meios de comunicação são atores poderosos porque têm força para influenciar e controlar a opinião pública. De fato, o quesito opinião pública “[...] é um conceito central nesse debate, como julgamento coletivo sobre determinado tema, que é capaz de influenciar as escolhas políticas" (SECCHI, 2015, p. 115). Dito de outro modo, como algo público e coletivo, o problema a ser sanado presume o interesse da população em assuntos que lhe são afins.

Outro tipo de ator importante são os think tanks: organizações atuantes em especial na análise e em pesquisas sobre políticas públicas. Diferem da empresa de consultoria porque se centram não só na aplicação, mas também na produção de conhecimentos em favor de mudanças organizacionais ou de políticas públicas. Também se distinguem do grupo de pesquisa acadêmica porque não produzem conhecimentos teóricos, pois se voltam ao aconselhamento, ou seja, repassam conhecimentos de aplicação imediata nas várias etapas do ciclo da política pública (SECCHI, 2015). Enfim, um think tank pode ser neutro quanto aos assuntos sobre os quais estuda e pesquisa, assim como pode defender causas específicas e atuar no ativismo para formar agendas. ${ }^{6}$

Em síntese, política pública é a ação que visa resolver o problema público, seja emanada do Estado ou quaisquer outros atores que ajam em vistas de solucionar tal problema. Por isso, pode envolver a sociedade civil, organizações não governamentais, o setor privado e outros atores cujos interesses os incluem no processo de dar solução a problemas de ordem pública. Essa compreensão incide, em parte, na ação dos atores — o que fazem.

Ainda que quem decida sejam agentes estatais, conceber políticas públicas como resposta a um problema de natureza pública que afeta a sociedade no todo ou em parte, supõe adotar uma forma de abordá-las como ação multicêntrica. Com efeito, ao conceituar políticas

${ }^{6}$ Think tanks brasileiros citados por Secchi (2015) incluem o Instituto de Pesquisa Econômica Aplicada, o Instituto de Estatística e Estudos Socioeconômicos e o Instituo de Estudos do Trabalho e Sociedade.

RPGE- Revista on line de Política e Gestão Educacional, Araraquara, v. 25, n. 1, p. 103-122, jan./abr. $2021 . \quad$ e-ISSN:1519-9029 DOI: https://doi.org/10.22633/rpge.v25i1.13650 
públicas, Secchi $(2015$, p. 4) se refere a uma abordagem multicêntrica, ou seja, um "enfoque mais interpretativo", que permite ao pesquisador ampliar seus horizontes porque o liberta de amarras político-administrativas estatais. Igualmente — argumenta o autor —, analisar políticas públicas pressupõe considerar que há correntes analíticas diversas, dentre as quais a positivista - que ele chama de racionalista - e a pós-positivista - também chamada por ele de argumentativa. Em seus estudos, Secchi (2016, p. 16) procurou conciliar tais vertentes, isto é, aproveitar a análise racionalista (positivista) e suas vantagens (metodologia simples e didática), e a análise argumentativa e suas ferramentas analíticas quantitativas (métodos participativos e deliberativos e pluralidade de atores).

Como diz Secchi (2015), a abordagem multicêntrica presume núcleos distintos na tomada de decisão os quais se amparam em um conjunto legal e institucional do Estado. Assim, se dada organização, entidade ou associação começar um trabalho ou uma campanha que pretenda resolver determinado problema da sociedade ou de uma comunidade — um problema público — guiados por uma política pública, estarão executando uma política pública; por menor que seja o problema. Ela pode ser replicada como modelo/base na ação ou em um programa de governo; e pode até ganhar mais abrangência que a da presunção inicial. Assim, a ação na qual o ator estatal se inspirou ou da qual se apropriou era uma política pública desde o início.

Visto que "A essência conceitual de políticas públicas é o problema público [...]”, no dizer de Secchi (2015, p. 5), então o que “[...] define se uma política é ou não pública é a sua intenção de responder a um problema público". Nesse caso, esboça-se aí uma compreensão da serventia das políticas públicas. Esse autor se refere à ideia de essência porque as definições de política pública seriam arbitrárias (SECCHI, 2015). De fato, cabe frisar: a definição de política pública não é consensual.

Políticas públicas são guias ou diretrizes para que uma ação planejada se concretize de dada maneira. Mais que isso, uma política pública elaborada para resolver certo problema público supõe seguir orientações e tomar medidas em prol da resolução. Heidemann (2009, p. 31) endossa essa compreensão ao escrever que

[...] a perspectiva de política pública vai além da perspectiva de políticas governamentais, na medida em que o governo, com sua estrutura administrativa, não é a única instituição a servir à comunidade pública, isto é, a promover "políticas públicas". 
A esse entendimento cabe acrescentar o que diz Majone (1989) sobre as relações entre política pública e discurso: a língua é parte da matéria de que é feita a política pública. Isso porque, seja de forma escrita ou oral, a argumentação permeia, fundamentalmente, as etapas do processo que redunda em uma política pública. A argumentação sustenta o debate, de tal modo que um sistema de governo, mesmo que seja ditatorial, pode ser chamado de governo marcado pelo debate. Nas partes pressupostas em um governo democrático — partidos políticos, eleitorado, os poderes (Legislativo, Executivo e Judiciário etc.), além da mídia e de grupos de interesse e especialistas independentes — , os debates e os mecanismos de persuasão estão presumidos em um processo contínuo (MAJONE, 1989). O pensamento de Goodin, Rein e Moran (2006, p. 12) amplia esse raciocínio quanto ao debate e à argumentação: “[...] governar é cada vez menos uma questão de comandar por meio de estruturas de autoridade hierárquica e cada vez mais questão de negociar através de uma série de alianças movediças" (tradução nossa).

Nesse contexto de política pública como fruto do debate e da argumentação, cabe dizer o que pensam Donahue e Zeckhauser (2006, p. 496) da chamada governança colaborativa, ou seja, da “[...] busca de objetivos públicos autoritariamente escolhidos por meios que incluem engajamento e esforço de, e critérios compartilhados com, produtores de fora do governo" (tradução nossa). Tais "produtores" são agentes aptos a participar da elaboração e tomada de decisões, bem como da execução da política pública (seus programas e suas ações em geral) em prol da resolução de problemas públicos delineados pelo governo. Tais partícipes integram o que, grosso modo, é conhecido como parcerias público-privadas, isto é, alianças entre os setores público e privado. Destas, deriva a formação de grupos de interesse, cuja participação se associa ao acúmulo de simpatizantes, dentre os quais a maioria ajuda a fortalecer a argumentação e, logo, criar poder decisório. É claro, quantidade não pressupõe proeminência. Esta é fruto muito mais do aumento de poder.

Com efeito, no jogo político, as relações de poder são força central. Quanto maior for o poder - institucional-legal, econômico ou de influência —, maior tende a ser a força de persuasão de um agente e de uma coalisão. Nesse caso, impõe-se o poder de controle e decisão. Como disse Foucault $(2017$, p. 369) “[...] o poder é um feixe de relações mais ou menos organizado, mais ou menos piramidalizado, mais ou menos coordenado". Logo, relações de poder existem não só nas instituições onde este está institucionalizado, a exemplo do Estado, da família, da escola, da prisão, do hospital e outros. 
O poder [...] deve ser analisado como uma coisa que circula, ou melhor, como uma coisa que só funciona em cadeia. Jamais ele está localizado aqui ou ali, jamais está entre as mãos de alguns, jamais é apossado como uma riqueza ou um bem. O poder funciona. O poder se exerce em rede e, nessa rede, não só os indivíduos circulam, mas estão sempre em posição de serem submetidos a esse poder e também de exercê-lo. Jamais eles são o alvo inerte ou consentidor do poder, são sempre seus intermediários. Em outras palavras, o poder transita pelos indivíduos, não se aplica a eles (FOUCAULT, 1999, p. 35).

Nessa lógica, obter poder supõe a aliança do discurso de grupos e indivíduos distintos, isto é, supõe o uso concreto da língua. Se assim o for, então cabe a constatação de que, uma vez cumprido o objetivo de obter o poder, a união e aliança de discursos alinhados entre si perde a unidade: cada partícipe passa a compor outra procura por poder. Afinal, como afirma Foucault (2014, p. 9-10), "Por mais que o discurso seja, aparentemente, bem pouca coisa, as interdições que o atingem revelam logo, rapidamente, sua ligação com o desejo e com o poder".

Essa compreensão se projeta no dizer de Goodin, Rein e Moran (2006, p. 23): “[...] a maior limitação na qual políticas públicas operam [...] é o puro egoísmo de interesses arraigados provido de poder suficiente para promover esses interesses das formas mais indefensáveis" (tradução nossa). Nesse ponto, o processo da política pública sujeita a sociedade - em especial o alvo da resolução de problemas — à ordem de interesses que, muitas vezes, podem ser escusos ou alheios aos fins da política pública porque são coniventes com o egoísmo. Caso se possa dizer que nem todos os atores interessados no bem comum, na coletividade tenham tais atributos de egoísmo, não se pode perder de vista que a sustentação de interesses (pessoais, de grupos menores etc.) na conquista de poder motiva o funcionamento da arena política. Cabe aqui a síntese de Goodin, Rein e Moran (2006, p. 27, tradução nossa): no fim, “[...] o apelo persuasivo retorna ao poder e aos interesses. Ou seja: política". Assim, eis a tônica das motivações e do funcionamento da política pública.

Em resumo: ainda que seja delimitado, o campo da ação política não é fixo, pois inclui possibilidades variadas em sua composição: a passagem do tempo; as crenças — que são mutáveis; a diversidade de instituições e líderes, dentre outros elementos que afetam a viabilidade de resultados. Como diz Galston (2006, p. 545), o "visionário" se separa do "excêntrico" por uma linha tênue não definível por algoritmo nenhum; e esse raciocínio aponta a ideia de que dificuldades e limitações se traduzem em contextos e variáveis numerosos que influenciam a dinâmica das políticas públicas. Mudanças mínimas alteram seu rumo e sua compreensão. Dado ator tido como visionário em certo momento, em razão de ideias arrojadas e revolucionárias, pode passar à condição de egoísta ou de demagogo em razão de mudanças em certa variável. Essa possibilidade posiciona a política pública como algo que pode ser RPGE- Revista on line de Política e Gestão Educacional, Araraquara, v. 25, n. 1, p. 103-122, jan./abr. $2021 . \quad$ e-ISSN:1519-9029 
delicado e frágil em função do grau de sujeição a que os projetos delineados como importantes submetem a sociedade.

Sobre o que são as políticas públicas, sua serventia e seu funcionamento, convém considerar a compreensão de Secchi (2015) na relação entre diretrizes de nível estratégico e de nível estruturante, distintas pelo posicionamento teórico de cada uma. Segundo esse autor, alguns estudiosos veem a política pública só como macrodiretriz, ou seja, como ações e programas concretizados. Nessa visão, a política pública seria algo estruturante, enquanto programas, planos e projetos seriam algo operante; isto é, estes compõem aquela, logo não têm individualidade. Como entende Secchi (2015) — entendimento que endossamos —, reconhecer uma política pública pelo nível de operacionalização da diretriz seria um critério inapropriado; tal delimitação pode excluir da análise, políticas para municípios, regiões, estados e organizações, também, configuradas como respostas a problemas públicos. Nesse caso, políticas públicas seriam a diretriz estratégica e diretriz operacional. Não por acaso, o construto teórico em torno da análise de políticas públicas supõe análise destas em outros níveis (o da região e o dos planos e programas).

Uma metáfora de Secchi (2005) é ilustrativa aqui. O autor toma o cabo de aço para analisar o ensino superior. O cabo seria uma macropolítica (algo estratégico) cuja formação inclui as "pernas" (o feixe de fios de aço), ou seja, programas e ações (algo operacional). No contexto deste trabalho, o cabo de aço seria a política de nível estratégico: expandir e internacionalizar as Instituições de Ensino Superior. As "pernas" seriam ações e programas afins a tal objetivo, dentre os quais o REUNI, o Ciência sem Fronteiras e o IsF. No caso aqui considerado - o IsF - , a metáfora pode se referir aos cursos on-line e presenciais, aos testes de proficiência e à instalação de NucLi, por exemplo, como os fios de cada "perna", isto é, níveis cada vez mais operacionais das três grandes ações do IsF.

Como se viu, os atores envolvidos na política pública podem ser coletivos organizações, meios de comunicação, opinião pública, policytakers e os think tanks — porque são formados por mais de um indivíduo. Além disso, as políticas públicas podem se sujeitar a possíveis influências e variáveis - e a interesses dos atores nelas envolvidos. Se essa descrição ajuda a entender quem são e o que fazem os atores, então cabe compreender as relações entre os grupos e as entidades de influência e de participação nas discussões e na execução de políticas públicas, assim como fases e etapas do que se conhece por ciclo da política pública. 


\section{Ciclo de políticas públicas}

Foram Stephen Ball e Richard Bowe (1992) que primeiramente refletiram sobre o ciclo de políticas públicas e o apresentaram. A apresentação supunha três contextos: a influência, a produção de texto e a prática, que são inter-relacionáveis e não lineares. A esses elementos se acrescentaram mais dois: os resultados (ou efeitos) e a estratégia política. Bastante difundido, esse modelo foi reformulado e reestruturado por outros pesquisadores, que até propuseram modelos cíclicos. Um deles foi o de Secchi (2015), cujo ciclo de políticas públicas resulta da combinação de outros modelos do arquétipo cíclico (e é a noção adotada neste estudo). O modelo desse autor inclui as etapas a seguir.

A etapa inicial é a da identificação do problema. Sua relevância está na seleção do que vai compor a agenda política de dado ator interessado na solução. Mas Secchi (2016, p. 50) alerta que "definir um problema" seria um desafio enorme no processo por causa da "[...] dificuldade de separar o problema de suas causas e consequências e de delimitar o problema em uma frase que capture a sua essência [...]", com a qual se relacionam as ideias de "excesso", "escassez" e "risco". A entrada no ciclo pressupõe que os atores envolvidos na resolução de um problema público o tenham enxergado e destacado. Assim, podem incluí-lo na agenda do governo $^{7}$ para, então, ser considerado como objeto de intervenção e se iniciar o ciclo da política pública afim. A agenda é a instância que reúne os vários problemas públicos a serem resolvidos.

A segunda etapa do ciclo da política pública supõe pensar no problema em questão: causas e formas viáveis de solucioná-lo. É o momento de propor e construir alternativas; ou seja, é o “[...] momento em que são elaborados métodos, programas, estratégias ou ações que poderão alcançar os objetivos estabelecidos. Um mesmo objetivo pode ser alcançado de várias formas, por diversos caminhos" (SECCHI, 2015, p. 48).

A terceira fase é a de construir alternativas. Atores diversos se unem para analisar o problema e refletir sobre possibilidades e vias de solução. Órgãos públicos, políticos, especialistas, grupos de interesse... todos se juntam (idealmente) para achar uma forma de elucidar o problema que lhes seja satisfatória. Dito de outro modo, fazer o programa ou a política sair do papel requer interpretar o ambiente para, então, planejar/organizar ações, tomar decisões acerca de benefícios e serviços a serem implementados e das fontes de recursos para

${ }^{7}$ Fala-se aqui de uma agenda governamental e de uma agenda do Estado. A primeira trata diversamente da agenda do Estado e, sobretudo, de problemas que dado governo (governante) é demandado a resolver. A segunda reúne continuamente problemas de certas áreas como saúde, educação, segurança e outras recorrentes nas preocupações estatais.

RPGE- Revista on line de Política e Gestão Educacional, Araraquara, v. 25, n. 1, p. 103-122, jan./abr. $2021 . \quad$ e-ISSN:1519-9029 DOI: https://doi.org/10.22633/rpge.v25i1.13650 
tal. Como diz Rodrigues (2015, p. 50-51), ocorre o desenvolvimento do apoio político à política em pauta a fim de que seja autorizada e legitimada.

A tomada de decisão é a quarta etapa do ciclo de políticas públicas. Feitos os estudos e as análises, é hora de construir consensos entre os atores para escolher uma alternativa adequada e coerente com os objetivos de resolução da problemática. Modelos teóricos distintos subjazem à tomada de decisão, cada qual com singularidades. Importa esclarecer os objetivos e as consequências de cada alternativa avaliada para que a escolhida possa ser a que vá maximizar os benefícios (MAJONE, 1989).

A fase seguinte à escolha do que vai ser feito é a da implementação, ou seja, da concretização, do pôr em prática o que foi pensado, analisado e elaborado como meios, ações programas etc., a fim de solucionar o problema. Implementar a política pública, então, é fazêla funcionar, atuar na sociedade/comunidade em prol da resolução do problema público que a motivou. Mas a implementação pode ser uma fase complexa, pois envolve atores terceiros passíveis de não ter envolvimento com a tomada de decisão, que podem pôr em relevo seus interesses específicos (individuais ou coletivas), quiçá interesses alheios ao problema inicial. Além disso, a fase da implementação é a que permite ver falhas da política pública, constatar erros de formulação, de tomada de decisão etc. Estes tendem a ter consequências traduzíveis em expressões como "leis que não pegam", "programas que não vingam" e outras. Inversamente, a fase permite constatar êxitos e consequências positivas. Não por acaso, políticas públicas que se tornam objeto de pesquisa, comumente, são abordadas pelos estudiosos nessa fase.

Com efeito, como diz Secchi (2015), a fase que possibilita rever aspectos da política implementada cria condições para perceber falhas e sucessos das fases anteriores, o que, por sua vez, abre margem para se pensar em correções e ajustes passíveis de aperfeiçoar a política pública. Trata-se de tarefa complexa no que se refere à maturação da política (SECCHI, 2015), a qual pode levar meses, até anos. Ante o fator tempo de maturação, a avaliação da adequação de uma política pública pode gerar expensas irrecuperáveis e até mais problemas.

O processo de criar uma política pública, implementá-la, avaliá-la e concluir que o problema que ela almejou mitigar foi resolvido culmina na extinção da política. Mas extinguila não quer dizer necessariamente findá-la; quer dizer que talvez vá ser aprimorada, reestruturada e/ou substituída por outra. É claro, dentro do ciclo de políticas públicas, governos/governantes têm autonomia para extingui-las em qualquer momento de sua 
existência; e não importam as razões (político-partidária, ideológica, orçamentária e de outra natureza) que justifiquem a extinção.

Essa descrição — de tom didático — das etapas do ciclo de uma política pública tem o fim de facilitar o entendimento de seu processo (surgimento, existência e funcionamento). Mas cabe frisar que nem toda política é passível de conter tais etapas, nem que as etapas se desdobrem na ordem descrita. Não só a ordem pode ser distinta, como também pode haver simultaneidade nas etapas. Pode acontecer de o ator político ter uma solução, mas o problema não estar reconhecido ou não ter o apelo necessário para se implementar a solução. Mais: subjacente a uma política pública podem existir outras políticas ou programas que a tornem funcional.

Em síntese, sejam quais forem os caminhos de dada política pública até sua concretização e extinção, convém frisar que o ciclo de sua constituição almeja tratar de um problema público que afeta uma parte ou o todo da população, de modo a eliminá-lo ou atenuálo; numa palavra, de modo a criar condições com o máximo possível de proximidade do ideal de justiça e de qualidade. É assim que o IsF se apresenta neste estudo: como política pública que pretendeu mitigar um problema público. Dadas as considerações feitas até aqui, convém apresentar tal política.

\section{IsF como política pública}

Nomes como REUNI, Universidade Aberta do Brasil, ProUni (acesso ao ensino superior) e FIES (financiamento do ensino superior), Institutos Federais de Educação, dentre outros, designam programas e ações voltadas ao ensino superior que formaram uma macropolítica ou uma política pública estratégica em prol da expansão e internacionalização da educação superior no Brasil. Nessa perspectiva, o programa IsF — criado em 2012, como Inglês sem Fronteiras, cabe lembrar - foi uma das ações de tal política pública educacional; uma política operacional.

Situado no contexto teórico-conceitual delineado até aqui, o programa IsF então se alinhou nos esforços para solucionar um problema público que se associa a um risco, uma escassez ou um excesso. Nesse sentido, o problema a ser resolvido era marcado pela escassez: a falta de proficiência em língua inglesa em meio aos universitários de graduação, sobretudo das Instituições de Ensino Superior públicas. A compreensão de tal problema apontou raízes variadas: educação com carga horária reduzida para disciplinas de língua estrangeira, escolas 
públicas com estrutura deficiente, professores sem preparo e qualificação, ensino de idiomas no Ensino Fundamental e no Médio através de metodologias obsoletas, dentre outros pontos.

Mais que reconhecer tal problema, era preciso elevá-lo à condição de preocupação do Estado e, logo, do governo; ou seja, era preciso que fosse notado em um contexto cuja influência fosse suficiente para ensejar uma tomada de atitude em prol de uma solução. $\mathrm{O}$ apelo do problema foi relacionado com o programa Ciência sem Fronteiras, cuja repercussão suscitou não só o desejo dos brasileiros de estudar no exterior, mas também a expectativa de docentes e pesquisadores de ter acesso a centros de pesquisa e de ensino renomados mundo afora. Assim, a falta de proficiência em língua estrangeira passou a ser vista como problema sério o bastante para chegar à agenda do governo federal, que viu naquele Programa uma de suas marcas significativas. Ainda que a falta de proficiência em línguas como o inglês fosse - e seja medida bastante objetiva do déficit na educação básica, foi o nível superior que motivou a política pública. O problema foi tratado no nível das consequências, e não do das causas.

O surgimento do IsF - como o próprio nome sugere - alinhou-se nas demandas e nos propósitos afins ao programa Ciência sem Fronteiras, ou seja, o IsF surgiu para suprir a necessidade do governo de suprir uma demanda dentro do Programa. Participar do Ciência sem Fronteiras - isto é, ir estudar em instituição universitária em outro país - exigia proficiência linguística dos participantes, e muitos não demonstraram tê-la. Além disso, havia problemas logísticos relativos à ida dos alunos para o exterior porque não tinham sido estruturadas vagas de acesso para fazer testes de proficiência. Assim, em uma demanda emanada da Presidência da República - à época personalizada nos reitores da Associação Nacional dos Dirigentes das Instituições Federais de Ensino Superior (ANDIFES) - a indicação de uma solução foi demandada pelo governo federal (ABREU-E-LIMA, 2017, entrevista).

É claro, o IsF não foi a única solução pedida; aliás, das outras soluções que surgiram ou foram encaminhadas, houve algumas que até se iniciaram. Mas o IsF foi a que vingou de fato, a ponto de ter sido desdobrada e continuar ativa. Com efeito, em entrevista concedida na pesquisa subjacente a este estudo, a presidente do IsF, professora Denise Martins Abreu-ELima, jogou luz sobre como a solução do problema se projetou na agenda governamental e como o IsF surgiu. Em suas palavras, a associação de reitores à época tinha como

[...] representante [...] nas Relações Internacionais [...] o meu reitor, da Universidade Federal de São Carlos, o professor Targino [de Araújo Filho]. Ele então me consulta, por eu ser especialista em educação a distância e em língua estrangeira - formação de professores - sobre a possibilidade de nós organizarmos uma proposta para encaminharmos à Secretaria de Educação Superior [SESu] (ABREU-E-LIMA, 2017, entrevista).

RPGE- Revista on line de Política e Gestão Educacional, Araraquara, v. 25, n. 1, p. 103-122, jan./abr. $2021 . \quad$ e-ISSN:1519-9029 DOI: https://doi.org/10.22633/rpge.v25i1.13650 
Como se lê, o delineamento da solução para o problema começou nas mãos de um professor, que contou com auxílio de uma professora, com a chancela da ANDIFES (área de relações internacionais) e com o trabalho de uma equipe a fim de conceber formas de auxiliar os estudantes. Sua entrevista detalhou, em parte, esse estágio do processo. Disse ela:

E, nesse processo, nós fizemos a seguinte proposta: em vez de dizer o que tinha de ser feito, juntamos especialistas de dez instituições brasileiras federais que já tivessem um percurso no ensino de inglês, formação de professores e pesquisa, tanto em mestrado e doutorado, e que tivessem um centro de educação a distância bastante consolidado. Porque, obviamente, as soluções que apresentaríamos teriam que envolver recursos à distância. [Também] que fossem regionalmente importantes. Nisso, selecionamos dez instituições. Dessas dez instituições, então, trouxemos um especialista em lingua estrangeira e o coordenador UAB [Universidade Aberta do Brasil] da época. Fizemos uma reunião em Brasília junto com o CNPq [Conselho Nacional de Pesquisa] e a CAPES [Coordenação de Aperfeiçoamento de Pessoal de Nivel Superior] em que eles puderam relatar toda a dinâmica do Ciência Sem Fronteiras e os problemas que eles estavam enfrentando. E passamos uns três dias desenhando o Programa (ABREU-E-LIMA, 2017, entrevista).

Essa passagem da entrevista permite entender que se passou à etapa de construção de alternativas. Com efeito, tendo em vista as etapas do ciclo de uma política pública, uma vez incluído na agenda, um problema público passa a ser objeto da formulação de soluções. Também cabe lembrar que nessa etapa, em especial, atores diversos estão passíveis de tomar parte no processo - nos estudos — de encontrar uma resolução para o problema. No caso do IsF, tais atores incluíram profissionais do ensino de língua inglesa e da área de educação a distância. Como tal, formaram um grupo individual não estatal: o "Grupo de trabalho Inglês sem Fronteiras".

Convém notar dois pontos: 1) atores de regiões variadas do País participaram da elaboração de soluções e alternativas para o problema identificado; 2) a presença de especialistas da área em que se situa o problema: a (falta de) proficiência em língua estrangeira. Dito de outro modo, o problema foi solucionado por uma equipe cuja formação não foi aleatória e contou com repertório de conhecimentos específicos para que fosse desenhado o Programa apresentado para solucioná-lo.

As causas do problema - cabe frisar - sugerem que o cerne do problema estava (está) na educação básica. Logo, a alternativa mais adequada seria investir na infraestrutura das escolas, na formação docente inicial/continuada e rever a reestruturação de metodologias e currículos. Também era de se pressupor que a etapa seguinte do ciclo do IsF como política pública - a tomada de decisão — enfocasse tal cerne após os estudos e a elaboração da solução RPGE- Revista on line de Política e Gestão Educacional, Araraquara, v. 25, n. 1, p. 103-122, jan./abr. $2021 . \quad$ e-ISSN:1519-9029 DOI: https://doi.org/10.22633/rpge.v25i1.13650 
(isto é, uma vez que fosse escolhida a alternativa mais viável e suscetível de ter êxito no enfrentamento do problema).

Contudo, a decisão tomada não atingiu a raiz do problema: as falhas na educação básica. A alternativa escolhida foi de intervenção (mais imediata) no ensino superior. Isto é, o alvo escolhido foi o fim, e não o começo; foi o topo, e não a base. A entrevistada — professora Denise Martins - tocou nessa questão. Ela disse que "Sim!": havia propostas cuja intervenção incidia diretamente na educação básica.

Mas não vingou. Até cheguei a participar de algumas reuniões, mas o problema também foi interno. As pessoas que estavam propondo não permaneceram e se a proposta está nascendo, não está muito bem estruturada, muda o gestor, ai se engaveta e começa tudo (ABREU-E-LIMA, 2017, entrevista).

De fato, pode-se presumir vários contextos tangenciando a escolha. Afinal, os atores envolvidos são diversos, e cada qual tinha intenções e prioridades subjacentes a suas decisões. Por exemplo, um contexto associável à escolha dessa medida — de feição paliativa preliminarmente - seria o da macropolítica, formada para expandir e internacionalizar a educação superior. Além disso, a gestão governamental é marcada pela transitoriedade dos que a assumem: o fim de um mandato político no governo pode pôr fim a um trabalho, aos esforços em prol de dada política. Dadas essas premissas, faz sentido escolher uma alternativa de efeito mais imediato, em detrimento de uma que pudesse levar mais tempo para produzir resultados (positivos ou falhas). Resultados esses que poderiam ser político-eleitorais.

Afora os motivos da escolha de dada alternativa, importa considerar a fase de implementação do IsF como política pública. Implementar o Programa supôs ações de níveis ainda mais operacionais, a exemplo da escolha e da compra de testes de proficiência, bem como da plataforma My English Online, de editais para credenciar universidades participantes, da criação dos NucLi, da seleção de professorado etc. A portaria de criação do IsF prescreveu a implementação e a formação discente virtual, bem como a aplicação de testes a cargo da Coordenação de Aperfeiçoamento de Pessoal de Nível Superior. Com efeito, a essa agência e só a ela - coube escolher um curso - o My English Online - e comprar senhas de acesso aos testes e os próprios testes (o TOEFL ITP). Por outro lado, a portaria 30/2016 — de ampliação do Programa — responsabilizou a Secretaria de Educação Superior — e só a esta — pela aplicação dos testes, como se percebe pela fala da entrevistada ao ser questionada sobre a compra de novos testes: "Não sei te dizer. Dessa parte eu não participo" (ABREU-E-LIMA, 2017, entrevista).

RPGE- Revista on line de Política e Gestão Educacional, Araraquara, v. 25, n. 1, p. 103-122, jan./abr. $2021 . \quad$ e-ISSN:1519-9029 DOI: https://doi.org/10.22633/rpge.v25i1.13650 
Embora as ações iniciais do IsF tenham sido direcionadas a grupos prioritários estudantes elegíveis para serem candidatos a bolsas do Ciência sem Fronteiras —, o IsF se expandiu aos poucos, de modo a abranger mais participantes e dar mais atenção à formação docente, inicial e continuada. Desse ponto em diante, veio a última etapa do ciclo da política pública: sua extinção; mais precisamente, sua reformulação. Com efeito, após ser implementado, houve expansões sucessivas do IsF: do público-alvo, da rede credenciada e dos idiomas ofertados, por exemplo. Convém frisar: a reformulação não substituiu ações nem público; ela os ampliou.

\section{Considerações finais}

Este trabalho buscou construir uma compreensão teórico-conceitual do Programa IsF como política pública para a educação. Tal construção inclui a compreensão de dois contextos subjacentes a uma política pública: em parte, sua concepção teórico-conceitual; em parte, os motivos e as necessidades que levam à sua proposição e criação. Nesse sentido, o IsF se apresenta como programa de ação de uma macropolítica: a da expansão do ensino superior em função do desenvolvimento da academia e sua internacionalização. Uma vez criado e implementado, o Programa se ampliou, evoluiu do foco inicial na língua inglesa, em 2012, para um foco que abrangesse outros idiomas a partir de 2014

Tendo em vista as etapas do ciclo do IsF como política pública, esse Programa presumiu quase todas; e isso mesmo sem que tenha havido estudos sistemáticos ou avaliação prévia da viabilidade e das necessidades ou operacionalidades exigidas pela criação e implementação. Também não houve foco na raiz do problema que o IsF veio ajudar a suplantar. Afinal, o ensino de idiomas não foi considerado no nível da educação básica, da qual os estudantes saem para chegar ao ensino superior com pouco conhecimento ou conhecimento nenhum de línguas, em especial do inglês, cujo ensino é obrigatório na educação básica. Mesmo que tenha havido proposições para ações em tal nível, o ensino superior foi o contexto de concretização de ações, o que engrossou a rede da macropolítica de expansão da educação superior.

Como política pública, ou seja, como algo que congrega interesses diversos, o IsF teve equívocos, problemas e falhas, na elaboração, implementação e condução; e mesmo que tenha funcionado como programa auxiliar ao Ciência sem Fronteiras — suspenso - o IsF se mantém ativo. Tal condição leva a pensar em um ponto fulcral da política pública: os investimentos. Continuar a política de expansão e internacionalização do ensino superior tende a ser ação 
inócua sem investimento na qualidade da educação oferecida, sem apoio ao desenvolvimento das ciências e sem tecnologia para produzir com inovação.

Com efeito, cortes orçamentários na educação afetam setores estratégicos ao desenvolvimento do Brasil, que tende a ficar em posição de atraso ante outras nações. Afinal, pode haver "evasão de cérebros" para países onde o desenvolvimento de pesquisas e as condições de vida são objeto de investimentos e oportunidades. Assim, a ação de situar a universidade e a pesquisa brasileira num plano internacional pode ser falha, caso não forem anuladas pendências internas (nacionais). Mais que a internacionalização, convém pensar em cooperação não só com instituições estrangeiras, mas também - e sobretudo - entre as instituições brasileiras, de modo a criar uma rede que permita superar limitações de localização dos grupos.

\section{REFERÊNCIAS}

ABREU-E-LIMA, D. P. M. Entrevista concedida a Eduardo José Pacheco em recepção de hotel. Uberaba, MG, 15 de dezembro de 2017. 2 arquivos de mp3 (23 min. e $102 \mathrm{~min}$.).

BALL, S.; BOWE, R. Subject departments and the "implementation" of National Curriculum policy: an overview of the issues. Journal of Curriculum Studies, Londres, v. 24, n. 2, p. 97-115, 1992.

BRITO, A. C. S. Inglês sem Fronteiras: contribuições para a internacionalização da educação superior brasileira. In: CONGRESSO DE EDUCAÇÃO DA GRANDE DOURADOS, 1. 2015, Dourados. Anais [...]. Dourados, MS: UFGD, 2015.

CHIZZOTTI, A. Pesquisa qualitativa em ciências humanas e sociais. 6. ed. Petrópolis: Vozes, 2014.

DONAHUE, J. D.; ZECKHAUSER, R. J. Public-private collaboration. In: MORAN, M.; REIN, M.; GOODIN, R. E. (Org.). The Oxford handbook of public policy. Oxford: Oxford University Press, 2006.

DORIGON. T. O programa Idiomas sem Fronteiras analisado a partir do ciclo de políticas. BELT, Porto Alegre, v. 6, dez. 2015.

DYE, T. D. Understanding public policy. Englewood Cliffs: Prentice Hall, 1984.

FOUCAULT, M. Em defesa da sociedade: curso no Collège de France (1975-1976). São Paulo: Martins Fontes, 1999.

FOUCAULT, M. A ordem do discurso: aula inaugural no Collège de France, pronunciada em 2 de dezembro de 1970. 24. ed. São Paulo: Loyola, 2014. 
FOUCAULT, M. Microfísica do poder. 6. ed. Rio de Janeiro/São Paulo: Paz e Terra, 2017.

GALSTON, W. A. Political feasibility: interests and power. In: MORAN, M.; REIN, M.; GOODIN, R. E. (Org.). The Oxford handbook of public policy. Oxford: Oxford University Press, 2006.

GOODIN, R. E.; REIN, M.; MORAN, M. The public and its policies. In: MORAN, M.; REIN, M.; GOODIN, R. E. (Org.). The Oxford handbook of public policy. Oxford: Oxford University Press, 2006.

HEIDEMANN, F. G. Do sonho do progresso às políticas de desenvolvimento. In: HEIDEMANN, F. G.; SALM, J. F. (Org.). Políticas públicas e desenvolvimento: bases epistemológicas e modelos de análise. Brasília: Ed. UnB, 2009.

LYNN, L. E. Designing public policy: a casebook on the role of policy analysis. Santa Monica: Goodyear, 1980.

MAJONE, G. Evidence, argument, and persuasion in the policy process. New Haven: Yale University Press, 1989.

MEAD, L. M. Public policy: vision, potential, limits. Policy Currents, n. 1, v. 4, Feb. 1995.

PETERS, B. G. American public policy. Chatham: Chatham House, 1986.

RODRIGUES, M. M. A. Políticas públicas. São Paulo: Publifolha, 2015.

SARMENTO, S.; KIRSCH, W. Inglês sem Fronteiras: uma mirada ao contexto de prática pelo prisma da formação de professores. Ilha do Desterro, Florianópolis, v. 68, n. 1, p. 4759, jan./abr. 2015.

\section{SCORTEGAGNA. B. A implementação do programa inglês sem fronteiras na} Universidade Federal do Rio Grande do Sul. 2013. 37 f. Monografia (Trabalho de Conclusão do Curso em Letras) - Instituto de Letras, Universidade Federal do Rio Grande do Sul, Porto Alegre, 2013.

SECCHI, L. Políticas públicas: conceitos, esquemas de análise, casos práticos. 2. ed. São Paulo: Cengage Learning, 2015.

SECCHI, L. Análise de políticas públicas: diagnóstico de problemas, recomendação de soluções. São Paulo: Cengage Learning, 2016.

SOUZA, C. Políticas públicas: uma revisão de literatura. Sociologias, Porto Alegre, n. 16, p. 20-45, jul./dez. 2006. 


\section{Como referenciar este artigo}

PACHECO, E. J.; CARVALHO, L. B. O. B. O Programa Idiomas sem Fronteiras como Política Pública Educacional. Revista on line de Política e Gestão Educacional, Araraquara, v. 25, n. 1, p. 103-122, jan./abr. 2021. e-ISSN:1519-9029. DOI: https://doi.org/10.22633/rpge.v25i1.13650

Submetido em: 15/05/2020

Revisões requeridas em: 30/06/2020

Aceito em: 28/10/2020

Publicado em: 02/01/2021 